\title{
Connecting aeolian sediment transport with foredune development
}

\author{
J.G.S. Keijsers ${ }^{1}$, A. Poortinga ${ }^{1}$, M.J.P.M. Riksen ${ }^{1}$ and A.V. de Groot $^{1}$ \\ ${ }^{1}$ Land Degradation \& Development Group, Wageningen University, P.O. Box 47, 6700AA, Wageningen, The Netherlands \\ joep.keijsers@wur.nl
}

\begin{abstract}
Foredune volume is an important factor for coastal safety and depends on the balance between erosion through wave attack and sediment input via aeolian transport. Dune erosion can be simulated with good accuracy, but predictions of aeolian sediment transport into the foredunes are still difficult to make. As part of a larger project that aims to model foredune development over decades, the goal of this study is to improve the understanding of the temporal variability in sediment transport at the beach. Measurements of aeolian sediment transport at the beach of barrier island Ameland show that within events, wind velocity and rain are dominant controls. After aggregating wind and precipitation into a single meteorological index, it was found that these controls alone are not sufficient to explain the year-to-year variability in foredune growth rates. In contrast to the volume changes, the variability in the amount of elevation change of the foredune slope can be related to the wind climate and precipitation.
\end{abstract}

\section{INTRODUCTION}

Aeolian sediment transport is an important process in coastal dune development. Together with dune erosion it determines foredune volume, which may form an important factor for coastal safety against flooding. Although dune erosion can be simulated rather well (e.g. Vellinga, 1986; Steetzel, 1993; Van Rijn, 2009), the sediment input to the foredunes is still difficult to predict.

Common equations for aeolian sediment transport as a function of wind speed or friction velocity were established for desert conditions. When these equations are applied in a coastal setting to estimate aeolian sediment fluxes under unsteady and heterogeneous conditions, the results are often dissatisfactory (e.g. Svasek and Terwindt, 1974; Arens, 1996, 1997; Bauer et al., 2009). An important cause for the discrepancy between predicted and measured fluxes is the influence of transport-limiting factors such as, slopes, surface moisture and lag deposits (Sherman and Hotta, 1990; Bauer et al., 2009). Recent approaches to predict sediment input to the foredunes therefore focus on identifying and measuring key variables, and filtering transport events from time series according to these key variables (Delgado-Fernandez, 2011).

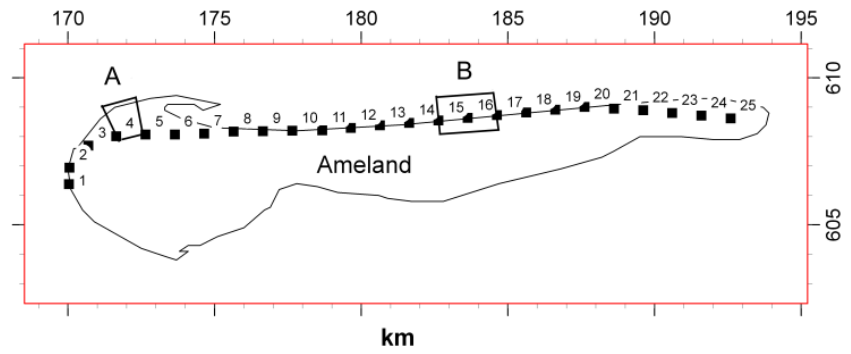

Figure 1. Location of field experiment (A) and the site for profile analysis $(B)$.
The goal of this study is to improve the understanding of the temporal variability in sediment transport at the beach. The hypothesis is that, given a steady beach configuration, temporal variability in sediment input to the foredunes is caused by variability in wind and precipitation. To test this hypothesis, the first part of this study quantifies aeolian sediment fluxes of events and identifies the dominant controls on a time scale of hours. The second part deals with year-to-year sediment input to the foredunes.

\section{METHODS}

\section{Study area}

This study focuses on the Dutch barrier island Ameland (Figure 1), measuring approximately $25 \mathrm{~km}$ in length and oriented west east. Its northern shore is flanked by a foredune ridge, ranging from 8 to $15 \mathrm{~m}$ in height and often backed by a more extensive and vegetated dune field. Storms are frequent in autumn and winter. In case of strong beach erosion during a storm or structural erosion beyond the safety limits, sand nourishments are carried out on the beach and nearshore to maintain or restore the sand volume. The site of the field experiment (A in Figure 1) has a beach width ranging from 150 to $250 \mathrm{~m}$. It is frequently nourished to maintain the 1990 coastline. At the coastal section used for profile analysis, beach width is approximately $100 \mathrm{~m}$.

\section{Short-term aeolian transport}

From October to December 2010, a fieldwork experiment was carried out on the beach of western Ameland (A in Figure 1) to measure the magnitude and temporal pattern of aeolian sediment fluxes in relation to meteorological conditions. Sediment transport intensity was measured using two saltiphones, giving the number of grain impacts per time unit. Mass fluxes were measured using Modified Wilson and Cooke catchers. Wind velocity was measured at a height of $2 \mathrm{~m}$ above the surface. Wind direction and precipitation were also recorded on site. A digital camera gave 
hourly overviews of the general field conditions. Measurements were analyzed per wind event, mostly lasting several hours.

\section{Medium-term dune development}

The Jarkus database of annual elevation profiles measured by Rijkswaterstaat was used to calculate annual values of beach width $(\mathrm{m})$, foredune volume above $3 \mathrm{~m}+\mathrm{NAP}\left(\mathrm{m}^{3} \mathrm{~m}^{-1}\right)$ and foredune activity index $(\mathrm{m})$. The foredune activity index (cf. Arens, 2004; Levin, 2006) is defined as the sum of absolute vertical elevation changes for all points on the foredune slope, divided by the number of points. Since 1996, the elevation profiles are measured using LiDAR. Therefore only data obtained from 1996 on were used in this analysis. We selected the section between km markers 14 and 16 (containing 11 profiles) as it has a relatively constant beach width throughout the period and shows homogeneous response to storm erosion (B in Figure 1).

\section{Climate-data analysis}

Hourly wind and precipitation data for the period $1996-2010$ were obtained from the Royal Dutch Meteorological Institute. These were measured at the neighboring barrier island Terschelling. To test the validity of these data for Ameland, the data of two other neighboring barrier islands were compared and these showed a high similarity in magnitude and timing of wind and precipitation records. The hourly wind data were aggregated into an annual meteorological index, in this case the onshore component (Davidson-Arnott and Law, 1990):

$$
U_{t o t}=\sum \cos \alpha_{i} \cdot\left(U_{i}-U_{t}\right)^{3}
$$

This incorporates the cosine effect of oblique winds (with incident angle $\alpha_{i}$ ) being less effective in transporting sediment across the foredune line than directly onshore winds. Offshore winds were discarded. Only hours having average wind velocity $U_{i}$ above the threshold velocity $\mathrm{U}_{t}$ and no recorded precipitation were taken into account. The resulting annual values are normalized against the highest occurring annual value.

\section{RESULTS}

\section{Field measurements}

During the two-month period, 15 aeolian transport events were recorded. A subset of 6 representative events was taken, with fluxes ranging from 3 to $16 \mathrm{~kg} \mathrm{~m}^{-1}$ (Table 1). Within events, the temporal variability was high, with transport intensity picking up

Table 1. Recorded data of 6 selected transport events (Poortinga et al., in prep.).

\begin{tabular}{ccccc}
\hline event \# & duration & $\begin{array}{c}\text { main wind } \\
\text { direction }\end{array}$ & $\begin{array}{c}\text { mean and sd } \\
\text { wind velocity } \\
\left(\mathrm{m} \mathrm{s}^{-1}\right)\end{array}$ & $\begin{array}{c}\text { sediment flux } \\
\left(\mathrm{kg} \mathrm{m}^{-1} \mathrm{~h}^{-1}\right)\end{array}$ \\
\hline 1 & 2 & $\mathrm{~h})$ & $3.7 \pm 0.4$ & 16 \\
2 & 21 & $\mathrm{SSW}$ & $5.4 \pm 1.0$ & 3 \\
3 & 13 & $\mathrm{NW}$ & $4.6 \pm 0.7$ & 3 \\
4 & 6 & $\mathrm{~W}$ & $7.0 \pm 1.0$ & 12 \\
5 & 11 & $\mathrm{SWW}$ & $10.0 \pm 1.2$ & 6 \\
6 & 8 & $\mathrm{~S}$ & $5.7 \pm 0.7$ & 4 \\
\hline
\end{tabular}

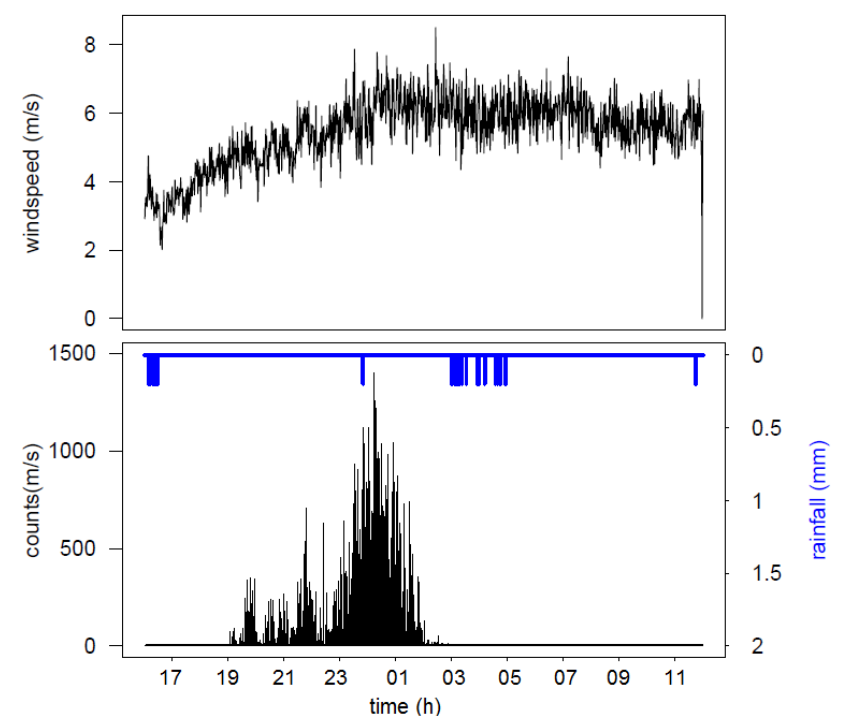

Figure 2. Wind speed (upper panel) and saltating particle count (lower panel) for event 2. Blue bars indicate precipitation (Poortinga et al., in prep.).

as wind speed increases and ceasing when precipitation occurs (Figure 2). At low wind velocities, transport was intermittent and transport was dominated by streamers. At higher wind velocities the saltating particle count was higher and more constant, indicating a continuous and higher transport rate.

Highest fluxes are associated with events with alongshoredirected winds, corresponding with the largest fetch lengths (Table 1). However, these winds are not directed towards the foredune zone, hence not directly contributing to foredune growth. There is no direct correlation between sediment flux and wind speed at this timescale.

\section{Elevation profile analysis}

Annual foredune volume changes for the 11 beach-dune profiles are given in Figure 3. Although a homogeneous section of Ameland was selected, the majority of the years contain both volume-gaining and volume-losing profiles. Furthermore, the year-to-year variation in the rates is high. In 1999 and 2008 all profiles have lost considerable volume, which indicates erosion. 1997 and 2009 are all positive. The average rate of foredune growth for this section over the period $1997-2010$ is $5 \mathrm{~m}^{3} \mathrm{~m}^{-1} \mathrm{y}^{-1}$.

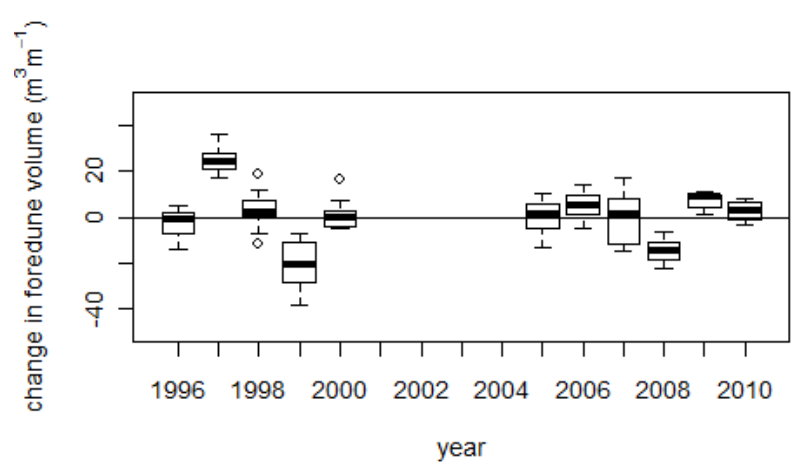

Figure 3. Year-to-year changes in foredune volume for location B. 


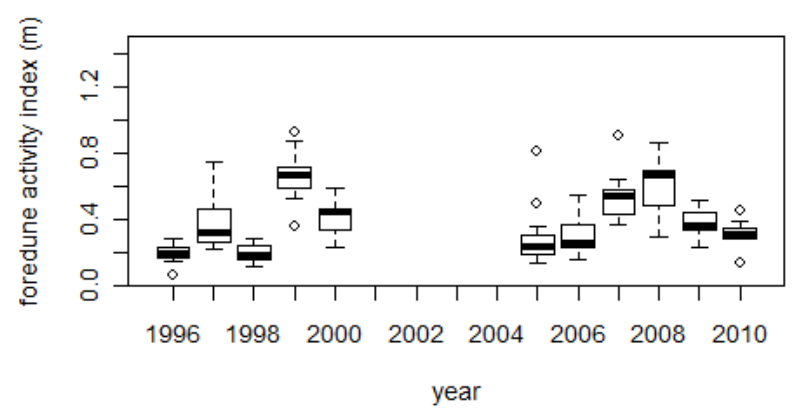

Figure 4. Magnitude and distribution of the foredune activity index at location $B$.

The annual activity index for the same profiles is given in Figure 4. A completely static foredune slope would have a value of 0 . There is considerable difference between the years, with highest values occurring in erosive years (1999 and 2008). In general, the activity index behaves like an absolute of the volume changes. In fact, the correlation between the absolute of the volume changes and the activity index is $0.88\left(R^{2}\right)$.

Figure 5 shows the annual foredune volume changes versus the meteorological index. There is no significant relationship between volume changes and the meteorological indices, even when only years with positive or negative volume change are considered.

Correlations improve when activity is considered instead of actual volume changes $\left(R^{2}=0.52\right.$, Figure 6$)$. Activity increases with increasing values of the onshore component, which means that there is more morphological change on the foredune slope for years with stronger onshore winds. For a similar wind index, this was also found for more inland dune profiles by Levin et al. (2006) and a Dutch parabolic dune (Arens, 2004).

The fit improves when hours with recorded rainfall are included in the calculation of the onshore component $\left(R^{2}=0.66\right.$,Figure 6$)$.

\section{DISCUSSION}

The year-to-year variability in foredune volume changes is high. By means of Monte Carlo simulation, we estimate the effect of the $0.15 \mathrm{~m}$ reported accuracy of the LiDAR technique (De Graaff, 2003; Sallenger, 2003) on the foredune volume calculation at $3 \mathrm{~m}^{3}$ $\mathrm{m}^{-1}$. This is in the same order of magnitude as the average volume

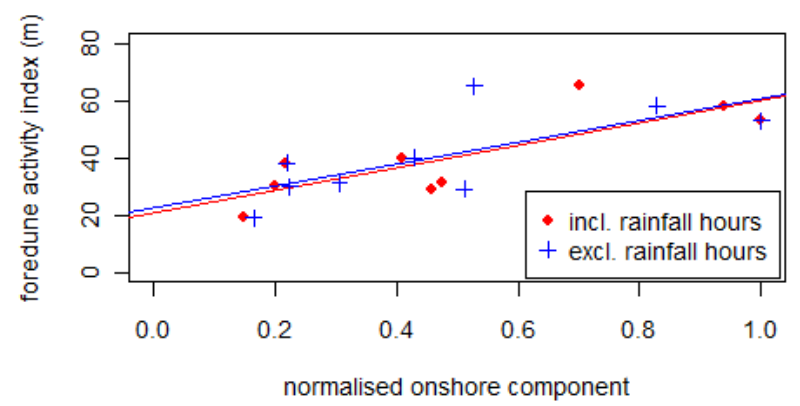

Figure 6. Foredune activity as a function of onshore component. Linear fits for both sets are given.

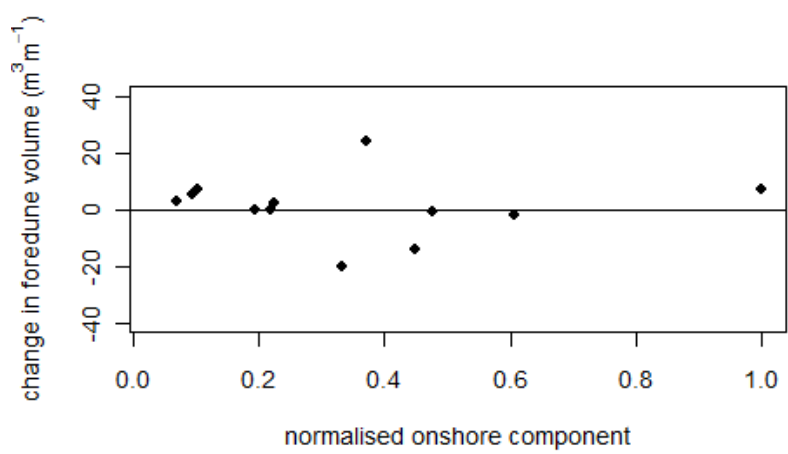

Figure 5. Yearly changes in foredune volume at location $B$, related to the onshore component of wind velocity.

change. The variability per year, illustrated by the width of the boxes in Figure 3, is however much larger, even though an apparently homogeneous stretch of $2 \mathrm{~km}$ was selected. This means there are others factors that generate spatial variability, e.g. the average beach height and nearshore morphology. These factors will be analyzed in the future.

Disputing the hypothesis, there is no significant correlation between annual foredune volume changes and meteorology in the form of the onshore component of wind. We believe this is mainly caused by foredune erosion. Although in most years the dunes gain volume, this does not mean that no erosion has occurred. In other words, the net foredune volume change is not always equal to the actual aeolian sediment input. To account for this, estimations of annual sediment input into the foredunes may be improved by simulating dune erosion volumes.

Because erosion also induces elevation changes in the foredune, the activity index correlates better to the onshore component of the wind. This means that when the onshore winds are stronger, the expected rate of morphological change or sediment redistribution on the foredune slope is higher. There is however no indication of the direction of the morphological change, i.e. growing or decreasing foredune dimensions.

\section{CONCLUSION}

Within aeolian sediment transport events, wind velocity and rainfall are important factors controlling the magnitude of aeolian sediment fluxes. There is however a large variation in transport intensity for events with similar conditions, indicating the presence of complicating factors that were not taken into account in the current measurement campaign.

Based on annual foredune volume changes, the hypothesis that variability in foredune growth rates is primarily caused by variability in wind and precipitation, cannot be confirmed. Although foredune volume gain is caused primarily by aeolian sediment transport into the foredune zone, there is no significant relationship between wind conditions and the volume change on an annual timescale. There is a significant correlation between the onshore component of the wind and the amount of elevation change on the foredune slope, but this does not indicate whether a foredune is growing or eroding. 


\section{ACKNOWLEDGMENTS}

JK and AdG are funded by Knowledge for Climate. We are grateful to Corjan Nolet and Saskia Visser for their support.

\section{REFERENCES}

Arens, S. M. (1996), Rates of aeolian transport on a beach in a temperate humid climate, Geomorphology, 17(1-3 SPEC. ISS.), 3-18.

Arens, S. M. (1997), Transport rates and volume changes in a coastal foredune on a Dutch Wadden island, Journal of Coastal Conservation, 3(1), 49-56.

Bauer, B. O., R. G. D. Davidson-Arnott, P. A. Hesp, S. L. Namikas, J. Ollerhead, and I. J. Walker (2009), Aeolian sediment transport on a beach: Surface moisture, wind fetch, and mean transport, Geomorphology, 105(1-2), 106-116.

De Graaf, H. J. C., S. J. Oude Elberink, A. E. Bollweg, Brügelmann, R., and L. R. A. Richardson (2003), Inwinning droge JARKUS profielen langs Nederlandse kust. Rep. AGIGAM-2003-40, Rijkswaterstaat.

Delgado-Fernandez, I. (2011), Meso-scale modelling of aeolian sediment input to coastal dunes, Geomorphology, 130(3-4), 230-243.
Levin, N., G. J. Kidron, and E. Ben-Dor (2006), The spatial and temporal variability of sand erosion across a stabilizing coastal dune field, Sedimentology, 53(4), 697-715.

Poortinga, A., J. G. S. Keijsers, S. M. Visser, M. J. P. M. Riksen, and A. C. W. Baas (in prep.), Aeolian sediment transport on the beach of Ameland: measuring aeolian sediment fluxes.

Sallenger, J., A. H., et al. (2003), Evaluation of Airborne Topographic Lidar for Quantifying Beach Changes, Journal of Coastal Research, 19(1), 125-133.

Sherman, D. J., and S. Hotta (1990), Aeolian sediment transport: theory and measurements, in Coastal Dunes: Form and Process, edited by K. F. Nordstrom, Psuty, N.P., Carter, R.W.G., pp. 1737, John Wiley \& Sons, Chichester.

Steetzel, H. (1993), Cross-shore transport during storm surges, University of Technology, Delft.

Svasek, J. N., and J. H. J. Terwindt (1974), Measurements of sand transport by wind on a natural beach, Sedimentology, 21(2), 311-322.

Van Rijn, L. C. (2009), Prediction of dune erosion due to storms, Coastal Engineering, 56(4), 441-457.

Vellinga, P. (1986), Beach and dune erosion during storm surges, University of Technology, Delft. 